DOI: 10.22559/folklor.911

folklor/edebiyat, cilt:25, sayı:99, 2019/3

\title{
Amerikan Şiirinde Avangart Geleneğin Elektronik Yansıması: Dijital Şiir
}

\author{
The Electronic Reflection of Avant-Garde Tradition in \\ American Poetry: Digital Poetry
}

\section{Memet Metin Barlık*}

\section{Öz}

1950'ler sonrası Amerikan şiirindeki öncü ekoller, geleneksel edebiyat normlarını eleştiren, gelişen ve yenilenen alternatif bir kültür oluşturarak, okuyucunun beklentilerini dikkate alan bir yaklaşım içinde olurlar. Black Mountain Şiiri (195056), Greenwich Village Şiiri (1950-63), Black Arts Akımı Şiiri (1962-70) ve New York ve San Francisco'nun Dil Şairleri (1979-89) gibi grupların başlıca yenilikçi ekoller olduğu görülür. Yenilikçi yaklaşım, yalnızca edebi alanda değil aynı zamanda müzik ve resim alanında da dikkat çeker. Resimde ekspresyonist yaklaşım ve müzikte Caz akımı görsel ve işitsel sanata yeni bir işlev kazandırır. Yazılı, sözlü ve görsel sanat dalları arasında gelişen iletişim, eserlerin dinleyici ve/ya izleyiciye sunumunu geleneksel kalıpların dışına çıkarır. Öncü grupların hedefi, kendi kişisel beklentilerini bir kenara bırakarak, gelecekte de kaliteyi sürekli kılacak eserler ortaya koymaktır. Güçlü bilgisayar teknolojileri ve tele-iletişim alanındaki yenilikler, e-kimlik, e-topluluk, e-eğitim ve dijital yaşam, dijital sanat ve dijital eleştiriyi içeren yeni sanal sanat sayfalarını doğurur. 'Tekno-yaşam' olarak adlandırabilecek bu sanal dünya, görsel ve yazınsal sanat dallarını da etkiler ve bu akımların elektronik nüshalarının doğmasına neden olur. Şiirin sanal medyadaki adı dijital-şiir, elektro-

Doç.Dr., Yüzüncü Y11 Üniversitesi, FEF. İngiliz Dili ve Ed. Bölümü. drbarlik@yyu.edu.tr 
nik şiir veya e-şiir olur. Bu makalede 1980'ler sonrası avant-garde akımın elektronik yansıması olan dijital-şiir incelenerek örneklendirildi. Teknoloji ve sanatın bir arada kullanımı ve fonksiyonları tartışıldı.

Anahtar sözcükler: avant-garde Amerikan şiiri, tekno-sanat, dijital şiir, e-şiir

\begin{abstract}
The avant-garde movements of American poetry after the 1950s, criticizing the traditional norms of the former periods, were eager to form an alternative renewing and developing culture, and tended to consider the demands of the populace of the readers. Black Mountain College (1950 - 56), Greenwich Village (1950 - 63), the Black Arts Movement (1962-70), the Language poets of New York and San Francisco (1979-89) were among the major avant-garde movements. The avant-garde approach was not only affective in literature but also in other genres of art, such as music and painting. The expressionist painting and Jazz music brought a new function to these genres of art. Avant-gardism also created a warm communication among different genres of arts, and changed the traditional norms of the presentation of the new forms. Powerful computer technologies and the new innovations of telecommunication created sites such as e-identity, e-education, digital art and digital criticism. The poetry created in this nominal world is called digital-poetry, electronic-poetry or e-poetry. Digital-poetry as a reflection of avantgarde movements of the 1980s is examined and illustrated in this paper.
\end{abstract}

Keywords: avant-garde American poetry, techno-arts, digital-poetry, e-poetry

\title{
Giriş
}

II. Dünya savaşı sonrası oluşan maddi ve manevi kayıp ve atom bombasının getirdiği kıyım, çağdaş veya postmodern denen Amerikan edebiyatına yeni bir yön kazandırır. "Büyük Depresyon döneminin kolektif ve emekçi romanı ile gündelik konuşma diliyle yazılan şiirin yerini hızla değişen farklı ekoller alır" (Wagner-Martin, 2013: 1). Modernizmin ciddi ve elitist yaklaşımı ve sonraki dönemin deneyimsel trendi, dini değerleri önemsemeyen, ironik bir tarza dönüşür; Ernest Hemingway, F. Scott Fitzgerald, Thomas Wolfe, ve William Faulkner'ın öncülük ettiği bilim-kurgu, gizem ve dedektif romanı baskın ekol haline gelir. 1920 ve 30'larda temelleri atılmış, siyahî, Yahudi, kadın ve farklı cinslerin ilişkilerini içeren edebi akımlar yeniden ivme kazanır. Harlem Rönesansı ile başlayan Afrika kökenli Amerikalı şairlerin başlattığı siyahî akım, 1940'lı ve 1950'li yıllarda da devam eder ve 1960/70 yıllarında Black Mountain ekolüyle şiir, "dönemin ırkçı ve politik bakışını ve sıradan insanların beklenti ve fikirlerini ele almaya başlar" (Halsey, 1995: 31).

1920'li yılların başlarında, T. S. Eliot, I. A. Richards ve William Empson'ın Yeni Eleştiri geleneğinden etkilenen John Crowe Ransom, Donald Davidson, Allen Tate ve Robert Penn Warren gibi şairler The Fugitive (Firariler) adında bir dergi yayımlarlar. Ancak 1930'lardan itibaren, dikkatlerini şiirden çok Güney'in entelektüel ve politik sorunlarına veren The Fugitive ismi değişir ve "Southern Agrarians" (Tarım Reformu Yanlısı Güneyliler) adını alır. Yeni 
Eleştiri akımına da yakın olan The Fugitive grubu, bir edebi metnin, içerdiği öz-yaşamsal bilgiden çok, metnin kendisinin üzerinde durulması gerektiğini, şiirin yakın/detaylı okuma tarzıyla (close-reading) analiz edilmesi gerektiğini gündeme getirir. The New Criticism (1941) adlı eseriyle bu alanda etkin olduklarını gösteren J. C. Ransom ve destekleyici grubu, 1930'lardan itibaren, farklı üniversitelerde, benimsedikleri anlayışı ders programlarına koyarlar. Böylece, “Yeni Eleştiri akımı 1960'lara dek etkin bir akademik çalışma alanı olarak varlığını sürdürür” (Beach, 2003: 138).

"1945'lerden itibaren, farklı ve zengin bir dönem yaşayan Amerikan şiirinde," (Bercovitch, 2007: 12) 1950'lerden itibaren, öncülügünü Robert Lowell, John Berryman, Randall Jarrell, Adrienne Rich, James Wright, Sylvia Plath, Anne Sexton ve Elizabeth Bishop'1n yaptığı İçgizemsel Şiir (Confessional Poetry) etkin bir akım olur. Nazik bir dil kullanmayı tercih eden içgizemsel şairler, doğrudan veya metaforik bir tarzla okuyucuyu şaşırtacak düzeyde özel konulara değinirler; "fiziksel veya ruhsal rahatsızlıklar, aile yaşamıyla ilgili hayal kırıklığı, cinsel tatmin veya yılgınlık, aybaşı hali, hamilelik, doğum, düşük yapma ve kürtaj gibi dişil fonksiyonları şiirlerinde yansıtırlar" (Kimmelman, 2005: 98). "Yoğun duygusal bir ton, öz-yaşamsal içerik ve anlatısal (narrative) bir yapıyla, sunumu birinci tekil şahısla yapmayı yeğleyen bu akım, okuyucu ile şair arasındaki mesafeyi en aza indirir” (Beach, 2003: 155).

1950’lerde geniş okuyucu kitlelerine ulaşan Beat Kuşağı, Lawrence Ferlinghetti'nin City Lights adlı basımevi ve kırtasiyesinde bir araya gelen ve Amerika'nın kendi kültürünü yansıtmayı, Batı'nın baskın medeni değerlerine tercih eden yazar ve şairlerden oluşur. Allen Ginsberg, Jack Kerouac, Diane de Prima, Anne Waldman, Richard Brautigan, Philip Whalen, Gary Snyder, Paul Blackburn gibi isimlerden oluşan bu kuşağın oluşturduğu protest kültürü, başlangıçta kabul görmese de sonraları “Amerika'nın estetik ilkelerini değiştiren bir düzeye ulaşır" (Wagner-Martin, 2013, 3). Aslında "birçok Avrupalı okuyucu için Beat Kuşağı şiiri, İkinci Dünya Savaşı sonrası dönemde, Amerika’yı en çok temsil eden şiirdir” (Ruland ve Bradbury, 1991: 395).

Yenilikçi (avant-garde) akımlar, Avrupa kadar olmasa da, Amerika'da okuyucu ve izleyici kitlelerini şaşırtmaya devam ederler; oluşturdukları yeni tarz ve ifade şekilleri, teknolojinin de katkısıyla, sosyal ve algısal bir değișimi beraberinde getirir" (Ruland ve Bradbury, 1991: 271). 1950’lerin sonlarına doğru, Deneysel Şiir geleneğini benimseyen yenilikçi akım, James Merrill ve Theodore Roethke gibi şairlerin öncülügünde, okuyucu ve basın dünyasıyla buluşmayı başarır. Yeni Eleştiri akımının akademik normlarını dışlayan bu akım, The New American Poetry (1960) adlı ontolojiyle, "altyap1, tarz ve tutumları farkl1, ancak deneyselcilik açısından paydaları aynı olan şairlerin tanınmasını sağlar” (Beach, 2003: 189).

Avant-garde geleneğin yansımalarından biri de, 1930'larda Robert Duncan'ın öncülüğünde kurulan San Francisco Rönesans şiiridir. Kenneth Rexroth, Charles Olson, Robert Creeley ve Denise Levertov'un da içinde bulunduğu bu akım, alternatif sanatsal ve edebi değerler yaratmayı hedeflerken, politik söylemlerle daha eşitlikçi bir toplum yapısının gerekliliği üzerinde yoğunlaşır. Bu ekolün hedefi, "entelektüel bilgi birikimini, tutkulu ve eşcinsel bir hayat istemiyle bir araya getirerek yeni bir tarz yaratmaktır” (Ellingham ve Killian, 1998: 9). 
Öte yandan, Charle Olson’ın Projective Verse (1950) (izdüşümsel şiir) başlıklı yazısının ilkelerini belirlediği The Black Mountain akımındaki Edward Dorn, Joel Oppenheimer, Jonathan Williams ve John Vieners gibi isimler, şiirde, 'açık-tarz' veya 'açık-şiir' diye adlandırılan yeni bir yaklaşımı benimserler. Projektif şiir olarak da tanımlanan bu ekolün öncüleri "şairin enerji ve doğaçlama gücünü en üst düzeyde yansıtarak yazdığı şiirin gerçek şiir olduğunu savunurlar" (Beach, 2003: 194). Okulun kurucusu olan William C. Rice "öğrencilerin belirli bir disiplinin veya kariyerin dayattığ geleneksel müfredattan çok, yeteneklerine göre yetiştirilmesi gerektiği görüşünü savunur; bu anlamda Black Mountain okulunun, Emerson'1n öz-güven öğretisini takip ettiği söylenebilir” (Halsey, 1995: 3,4).

John Ashbery, Frank O’Hara, Kenneth Koch, Ted Berrigan ve James Schuyler gibi şairlerden oluşan ve New York'un avant-garde akımı, Manhattan'ı bir uluslararası sanat merkezi olarak görür. Soyut içerik ve nükteli bir anlatı üslubunu benimseyen New York Okulu şairleri, edebiyatın diğer sanat dallarıyla etkileşiminden doğan yeni bir estetik anlayışın arayışında olurlar. Romantik geleneğin lirik anlatı tarzını dışlayan New York Okulu, şiirin yalnızca şairden okuyucuya iletilen özel mesajlardan ibaret olmadığı, farklı düşünce ve aktarım tarzlarının denenmesi gerektiği görüşündedir. Bu şairler "yeni yöntemler geliştirmenin riskli olduğunu, ancak sanatı tekdüze ilkelerden kurtarmak adına farklı kazanımların sağlanabileceğini savunurlar" (Fredman, 2005: 116).

"Yirminci yüzyıl şiirinin en büyük özelliklerinden biri de, daha yerinde ifadeler bulmak ve estetik açıdan hoşa giden bir tarz yaratmak adına, dilin normal kullanım alanının ötesinde kullanılmasıdır" (Jeffries, 1993: 5). Şiiri, dilin kendisini keşfetmek için kullanılması gerektiğine inanan avant-garde şairler, Dil Şiiri (Language Poetry) denen bir akımın doğmasına öncülük ederler. 1980 ila 90 yılları arası dönemde baskın olan bu yaklaşım, şiirin sosyal ve politik eleştiriyi yansıtan bir sanat dalı olabileceği görüşünü benimserler. Dil Şairleri, sosyal, kültürel ve edebi söylemlerin dil aracılığg ile keşfedilmesinin, sanatın hedefleri arasında olması gerektiğine inanırlar. 1978-81 yılları arası yayımlanan $\mathrm{L}=\mathrm{A}=\mathrm{N}=\mathrm{G}=\mathrm{U}=\mathrm{A}=\mathrm{G}=\mathrm{E}$ dergisiyle okuyucuya ulaşan Dil Şiiri "akademik olmayan, teori bilinçli, avant-garde, post modern ve muhalif şiir” olarak tanımlanır” (David, 2007: 1).

1980'lere gelindiğinde, Amerikan şiirindeki yenilikçi gelenek bireysel tarzlarla okuyucuya ulaşır. 1973'te Bolingen ödülüne layık görülen James Merrill ve 1975 'te A. R. Ammons'u 1977'de David Ignatow takip eder. 1960'larda Donald Allen tarafindan yayımlanan The New American Poetry antolojisinde yer almayan Merril, The Changing Light at Sandover (1980) adlı eseriyle, deneysel şiiri yükseklere taşımayı başarır. Bir Kuzey Carolina şairi olan A. R. Ammons da, kendi çizgisini oluşturan şairlerdendir; şiirlerinde doğayı ana tema olarak işlediğinden, doğa-şairi olarak bilinir. 1972'de yayımlanan Collected Poems 1951 - 1971 adlı eseri Ulusal Kitap ödülüne layık görülen Ammons, Sphere (1974) başlıklı çalışmasıyla 1975’te Bolingen ödülüne layık görülür.

William Carlos Williams ve onun takipçileri olan Louis Zukovsky ve Charles Reznikoff gibi şairleri esin kaynağı alan David Ignatow, şiirlerinde kullandığı vezin, dil, kendine özgü güçlü mizah tarzı ve gerçeküstü temalarıyla genç kuşağı etkilemeyi başarır. Michigan Devlet Üniversitesinde hoca olan Diane Wakoski, Ignatov'un takipçisi olarak kabul edilir. Wakoski, William Carlos geleneğinin ve içgizemsel şiirin dışında, kendi kişisel mitolojisini oluşturan 
bir şairdir. Şiirlerinde hayali kimlik arayışı ön plana çıkan Wakoski'nin The Diamond Dog (2010) adlı eseri, söz konusu (hayali) temayı işlediği eserlerindendir. 1980'de Satan Says adlı eseri yayımlanan ve Adrienne Rich takipçisi olan Sharon Olds, samimi dil seçimi ve kişisel temaları ile dikkat çeker. Öte yandan, içgizemsel şiir geleneğini kendine özgü bir tarza dönüştüren Ai, sanal dramatik monologlar içeren metinlerle okuyucuya ulaşır ve Vice: New and Selected Poems (1999) adlı eseriyle şiirde Ulusal Kitap ödülüne layık görülür.

Sacvan Bercovitch'e (2007) göre, XX. yüzyılın sonlarına doğru, bireysel tarzların oluşmasına dönüşen Yenilikçi (avant-garde) sanatçının ilkeleri şöyle sıralanabilir:

- Kişisel yeti ve donanımlarını ön plana çıkarma isteğinden çok, gelecekte baskın olacak sanatı üretme amacına motive olmak.

- Bu amacı gerçekleştirmek için farklı medya gruplarıyla, sanatçıların katıldığı halk konfederasyonları oluşturmak.

- Çağdaş sanat topluluklarının benimsediği kalıplara karşı çıkmak ve

- Toplum ve sanat arasındaki bağ ile ilgili açık bir görüşe sahip olmak (s. 83 ).

“'1960’lardan 80'lere kadar yenilikçi akımların değişen safhalarına tanıklık eden Postmodern dönem, entelektüel dünyanın, beklenenin üzerinde farklılaşan bir tekno-yaşama dönüştüğünü gösterir" (Ruland ve Bradbury, 1991, 393). Sanal medya sayfalarında, e-şiir, e-roman veya e-eleştiri ürünleri okuyucu kitlelerine ulaşır. Bu katılımcı ve enteraktif sunum, bireysel, ideolojik ve deneysel estetik kavramların, medya aracılığıyla dijital sanat sayfalarında buluşmasını sağlar. Böylece, tekno-yaşam kültürünün getirdiği yeniliklerle sanallaşan Deneysel Şiir yeni bir sunum şekliyle okuyucuya ulaşır; buna, "bilgisayar teknolojilerinin kablosuz özelliklerinden ve internet imkânlarından yararlanılarak oluşan, 'Dijital-Şiiir'” denebilir (Ledesma, 2016: 81).

\section{Dijital şiir}

Bir deneyimi paylaşmak söz konusu olduğunda, teknolojinin kaçınılmaz bir paylaşım aracı olduğu gözlenir. Özellikle bilim ve teknolojiyle, politika ve sanatı bir araya getiren farklı medya araçları; basın, sinema, radyo, televizyon, bilgisayar, internet vs. deneyimsel sanatın sunumu, paylaşımı, beğenisi ve eleştirisini hızlı ve kolay hale getirir. Kısaca, "teknolaştırma (technologizing) anlatı sanatı ve sanatçıları için, basın dünyasındaki formalite ve hiyerarşiyi devre dışı bırakarak, kültürel ürünlerde yeni yüzlerin tanıtım ve dağıtımında büyük olanaklar sağlar" (Amerika, 2007, 413). Yazılı sanatların dijital yansıması adlandırılırken akla ilk gelen başlık 'Elektronik Edebiyat' başlığıdır. Elektronik edebiyat “genellikle basılı edebiyatı devre dışı bırakan ve ilk-metin oluşumu dijital ortamda başlayan, kısaca, bilgisayar ortamında üretilen ve yine bilgisayar ortamında okunma beklentisi olan edebi metinleri içerir” (Hayles, 2008: 3).

“1980 ila 90 yılları arasında ilk örneklerine rastlanan bilgisayar-şiiri (computer-poetry), metinsel distopyada, benzer özellikleri olan eserlerin yer arayışını ve dijital şiir metinlerine olan gereksinimi” gündeme getirir" (Glazier, 2002: 3). Elektronik ortamda üretilen ve elektronik ağ üzerinden paylaşılan e-edebiyat metinleri için, aynı ortamın dijital kültür sayfalarında; örneğin, bilgisayar oyunları, filmler, animasyonlar, dijital sanatlar ve görsel kültür sitelerinde bilgilendirme yapılabilmektedir. 1999 yılında kurulan Elektronik Edebiyat Or- 
ganizasyonu, elektronik edebiyatı, “önemli edebi özellikleri olan metinlerin, özel veya ağ bağlantılı bilgisayarların sağladığı bağlam ve olanaklardan yararlanması" şeklinde tanımlar" (Simanovski, 2011: 27). Ancak reel basın dünyasındaki eserlerin üretilmesi, edebi özellikler açısından değerinin belirlenmesi ve basılı metinlerin okuyucu kitleler tarafından kabul görmesi aşamalarının dijital edebiyat koşullarıyla örtüşmediği görülür.

Yazılı sanatın görsel ve işitsel dünya ile yarışı anlamına gelen bu teknolojik görüngü, edebi akımların hemen tüm dallarına yansır ve e-eleştiri, e-roman, e-öykü ve e-şiir/dijital şiir gibi adlandırmaların oluşmasını sağlar. "Yirminci yüzyılın son dönemlerindeki deneysel şiir, çağdaş teknolojiyle bir araya gelir ve kitlesel medya aracılığıyla görsel ve işitsel imgeleri tüketen 'Dijital Şiir' adını alır”' (Ledesma, 2016: 81). Böylece, deneyimsel şiirin somut-şiir (concrete-poetry), fonetik şiir (phonetic poetry), polinom-şiir (polypoetry), kod-şiiri (codepoetry) ve siber-şiir (cyberpoetry) gibi alt yansımaları da ortaya çıkar. Dijital şiir, görüntü, ses ve metinden oluşan bir sanata dönüşür; ses, hareket ve video teknikleriyle yeni ve farklı sunum olanaklarına da kavuşan e-şiir, hızlı erişim imkânlarıyla, bilgisayar ekranlarını okuyucuya ulaştığı platform olarak kullanır ve kopyalanabilen, geliştirilebilen ve ilave edilebilen bir edebi metin iletişimi haline gelir.

“Görsellik fonksiyonu dilbilimsel öğelerle bir arada kullanmakla önemi anlaşılan akım Somut Şiir (concrete-poetry) olarak adlandırılır” (Simanovski, 2011: 28). Amerikan şiirinde, ilk örneklerine Emmet Williams'ın (1925 - 2007) somut-şiirinde rastladığımız programlanmış şiiri (programmed poetry), Jackson Mac Low, George Brecht, Dick Higgins ve Robert Filliou gibi isimler benimser ve aynı tarzı bir ekol haline getirirler. Williams, "Almanya'da gelişen Fluxus akımının somut, avant-garde ve sunumu önemseyen tarzı onaylar ve sıralamaS1 değişen, tekrarlanabilen, sadelik ve nesnelliği ön plana çıkaran (minimalist) eserler üretir" (Glazier, 2002: 127).

Loss Pequeño Glazier, Poems for the Millennium: The University of California Book of Modern \& Postmodern Poetry (1998) adlı eserin II. Cildinde, Emmet Williams'in programlanmış şiirine What başlıklı şiiri örnek verir ve şöyle analiz eder:

What

Into dew up lark

mango dove lark flight

thrush song into

white shadow

even up dot certain (Rothenberg ve Joris, 1998, 214).

What şiirinde, başlıktaki kelimeleri temsil eden alfabe düzeneği göze çarpar; bu dizin, sonraki dizelerin oluşumuna kaynaktır; açıkça görülüyor ki w = "into," h = "dew," a = "up," ve $\mathrm{t}$ = "lark"; buradan "into" gösteriyor ki i = "mango," ve sonraki satır, "mango dove lark flight” birinci satırın başındaki ilk dizin olan "into" kelimesinden üretilmiştir. Programlanmış şiirin oluşumu bu örnekte görülen bir metodu takip eder (Glazier, 2002, 128).

1960'l1 yıllardan itibaren 'programlanmış şiir' konusunda adından söz ettiren Jackson Mac Low, (1922 - 2004) 'tahmin edilmez' (unpredictable) diye tanımladığ 1 şiirinin esinini John Jage'in 1950 / 60'larda uyguladığg 'şans-güdümlü' (chance-operational) şirinden aldı- 
ğını ve bu yöntemle "hedef metnin kontrolünün şairin kendisinde olmadığı bir şiir metninin ortaya çıktığını iddia eder. Mac Low, 'hedef şiir' (deterministic poetry) yönteminde ise, 'kök metin' ve 'tohum metin' (source text, seed text) denen iki kaynaktan hareket edildiğini ve bu metinlerin şairin kendisi ve başkaları tarafından yazılmış olabileceğini aktarır. Ancak şans güdümlü programlamanın tersine, hedef metni elde etmede başarılı olmanın ilkesinin, yöntemi eksiksiz uygulamakla olabileceğini savunur ve bu yöntemi, "metin seçkisiyle akrostiş okuma" diye adlandırır (Low, 2008: 30).

Mac Low, “yazma şekilleri” ya da "sanat üretme yolları”, (art-making-ways) diye adlandırdığı programlı şairlik kariyerinin 1990’lar ve 2000’lerin başından itibaren yön değiştirdiğini söyler:

Şimdi tüm yazım şekillerini (ve diğer sanat üretme yollarını) değerli buluyorum. 1990'lar ve 2000'lerin başından itibaren yazmada iki temel yol takip ediyorum. Her iki şekilde de tesadüfün önemli payı var, ancak 1990'dan önce yazdıklarımdan farklıdırlar. Ekim 1990'dan 1995'lerin başına kadar, 154 Forties şiir serisinin ilk metinlerini yazdım ve o tarihten bu yana onların üzerinde değişiklikler yapıyorum. Forties şiirlerini dış veya iç çevremden kelimeler, ifadeler 'toplayarak' yaptım; ilk metinlerini yazarken gördüğüm, duyduğum ya da düşündüğüm kelime ve ifadeler. Sonraki dönem onları yeniden gözden geçirmekle geçti. Her şiir 'belirsiz yazın şekliyle' yazılı sekiz ya da beş satırdan oluşan kıtalardan ibaret; bu kıtaları üç kısmen daha uzun satırlar takip eder, sonra oldukça uzun bir satırı kısa bir satır takip eder (Low, 2008: 33).

Tüketici toplumun yapay yaşam değerlerinin 'tekno-kültürle' edebi sanata yansımasını örneklendiren Mac Low, şiir yapmadaki/yazmadaki hedefini şu sözlerle açıklar: “dijital programlama yöntemi ile elde edilen çıtıdan şiirler yapıyorum ve bu şiirler belirli koşullarda özgür kompozisyonlar oluşturmaya ham madde oluyor' (Low, 35). Mac Low'un 'Program Şiirleri', Anne Tardos'un editörlüğünü yaptığı Thing Of Beauty: New and Selected Works (2008) adlı eserinden alıntılanarak aşağıda örnek olarak verilmiştir:

\section{Asymmetry 18}

inspiring.

name sins people instruction

reverent "invoking"

name

[Goblins]

name

Avalokitesvara

magical enables (Low, 2008: 84).

\section{Asymmetry 138}

but his Italian voyage,

"Under the sun"

the same vigour of life:

“Unter der Sonn” (Low, 2008: 87). 


\section{Net Murder 1}

Now jeopardizes catch.

More huge stretched land.

Marketable fishermen after stopping salmon leverage sea.

Nets were nets more hundred birds.

Murder stake,

summer and

other small seals.

Least netting,

sea into mysterious our farther used indeed,

require accepting at sea

be.

Sea now jeopardizes catch.

3 August-11 September 1990 New York

(Low, 2008: 325).

\section{Flaming held fast}

Flaming air sleeveless and charmless broken on Tertiary rocks common ámphora known too soon prophetic excused drivel primeval búllet-proof máke-believe vest burning on the Plasticine rug spíndle-fly losing pearly-gólden appetite extending to humdrum singing streets' antagonistic eaves installed triangular clubs

Tick-tock mud in the wilderness ruin cast into additive fever amorphous strophes of rock unclasped by thankful articulate seams silvery wildness ungathered across the throat's conundrum example expected arms present in lesions swelling in kerosene pictures falling from nails clustered in riotous poetry never infused with ecstacy bubbles surmised by plumes

Debris leaking-serendípity polishing stainless steel revisions weeping caldrons of filigreed ash mediated by mirth spilled out at home vertigo mimosa twisted by fate in a slavish future crawl repressive semantic decaying in laminated songs' logical drawing rooms manacled manual waters of photography

partial cellar moons (Low, 2008: 364). 
Mac Low, Twenties 100 Poems (1991) adlı eserinde de şansa, hedef metin belirlemeye, sezgisel ifadelere ve anlamı belirsiz dizelere dayalı şiirler yazmayı sürdürür ve sonraki dönemlerde müzik ve şans şiirini bir araya getirdiği dijital programlama şairliğine devam eder.

Dijital şiiri, algoritmik nota programlarından esinlenerek elde etmeyi deneyen John Cage, (1912-1992) bu geleneğin temsilcilerinden bir müzisyen ve şairdir. Cage, "politika, toplum ve sanatta çoğulcu bir yaklaşımı benimser ve bu felsefeyle dünyadaki kültür farklılığını oluşturan her bir bireyin eşsiz olduğuna inanır" (Bernstein, 2001: 1). "Müzik kelimesinin 18. ve 19. Yüzyıl için 'kutsal ve korunması gereken' bir kelime olduğunu” ifade eden Cage, "yeni kuşağın onu 'seslerin organizasyonu' tanımlamasıyla daha anlamlı bir düzeye getirmesi gerektiğini savunur” (Cage, 1961: 3).

Writings Through John Cage's Music, Poetry, and Art (2001) adl1 eserde David Bernstein, John Cage'in sanatsal yetileri ve sanata bakışını şu sözlerle ifade eder:

Kariyeri boyunca Cage, avant-garde müzisyenlerin, sanatçıların ve yazarların propagandasını ve provokatörlüğünü yaptı, müzikte, notaların birleşiminden oluşan herhangi bir melodinin ya da gürültünün estetik açıdan hoşa gidebileceğine; bu nedenle müzik yapmak için materyalin sonsuz olduğuna inandı... yaratıcı enerjisi müzikle sınırlı değildi ve aynı zamanda yetenekli bir yazar olan Cage, yedi albümü, denemeleri ve şiirlerinin yanı sıra, baskı-resim ve suluboya gibi görsel sanatlarda da donanımlı bir sanatçıydı (Bernstein, 2001: 2).

Cage, 1970'lerden itibaren yazar ve şairliğe yoğunlaşır ve 36 Acrostics Re and Not Re Marcel Duchamp eseriyle, çeşitli programlamalarla kelime ve harflerle oynayarak, 'akrostiş veya mesostik' diye adlandırdığı sözlüksel şiiri (lexical poetry) elde etmeye çalışır: örneğin, Edwin Denby adında bir arkadaşına yazdığı dizeleri aşağıdaki gibi dizayn eder:

rEmembering a Day I visited you—seems noW

as I write that the weather was theN was warm- $-\mathrm{i}$

recall nothing we saiD, nothing wE did; eveN so

(perhaps Because of that) that visit staYs (Silverman, 2010: 200).

Düz yazı şeklinde yazılmış bu paragrafın içine arkadaşının isminin (Edwin Denby) harflerini büyük harflerle serpiştiren şair, sonraki dönemlerde daha şiirsel metinler yazmayı hedefler. Geliştirdiği satranç tarzı oyunlarla elde edilen beş ve yedi mısralık kıtalarda, işlemek istediği isimlerin harflerinin her birini, dizeleri oluşturan kelimelerin içindeki uygun harfi büyük yazarak öne çıkarır ve bu yöntemi “mesostics” diye adlandırır. Aşağıdaki şiir 'MARCEL' isminin işlendiği, Cage programlamasıyla elde edilen bir şiirdir:

questions i Might

hAve

leaRned

to ask Can

no longEr

receive repLies (Silverman, 2010: 200). 
Jackson Mac Low gibi John Cage de "Fluxus grubunun faaliyetlerine katılır; bu aktivist grup geleneksel karşıtı, uluslararası sanatçı, şair, besteci ve sunuculardan oluşan ve sanatın sınırlarını genişletmeyi hedefleyen yenilikçi sanatçılardır" (Bernstein, 2001: 235). John Cage'in 1979 yılında yayımlanan Empty Words Writings '73-'78 adlı eserinden 'mesostics' diye tanımladığı program şiiri aşağıda örneklendirilmiştir:
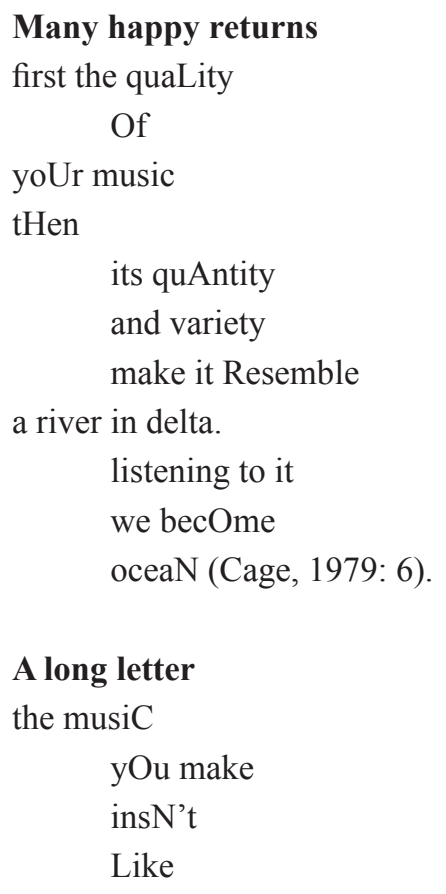

any Other:

thaNk you.

oNce you

sAid

wheN you thought of

musiC

you Always

thought of youR own

neveR

Of anybody else's.

that's hoW it happens (Cage, 1979: 6).

Dijital şiir geleneği, çağdaş Amerikan şairler tarafından da benimsenen bir akımdır; örneğin, Ron Silliman (1946- ) Tjanting (2002) adlı eserindeki Fibonnaci şiir serisiyle program şiirini örneklendiren isimlerdendir (Glazier, 2002: 132). Lyn Hejinian'ın, 37 metinden oluşan My Life eserinin ilk baskısında, her bölüm bir yıla tekabül eder ve 37 'şer mısradan 
oluşur. Sekiz yıl aradan sonra, Hejinian eserindeki bölüm sayısını 45'e çıkarırken, her bölüme de sekizer misra ekler (Glazier, 2002: 132). Böylece, değiştirilebilen, ekleme yapılabilen programlı şiir, Hejinian'ın geliştirdiği yeni tarzla, rakamsal birtakım öğelerle, öz-yaşam ile metinler arasında bağ kuran bir boyut kazanır.

\section{Sonuç}

Bilimin sanat ile olan etkileşiminde, iki önemli işlevi olduğu gözlenmektedir; birincisi sanatsal değeri olan eserlerin bilim tarafından keşfedilmesi, ikincisi ise, sanatın kültürel boyutunu aktif bir boyuta taşımasıdır. Bilimin gündelik yaşamın bir parçası konumuna getirdiği teknoloji, sessiz olana ses veren, saklı olanın bilinmesini sağlayan, bireysel ve/ya toplumsal bilinçaltı dünyasının yasakları aşarak, dilin içerdiği çeşitli sembollerle paylaşılmasını sağlayan bir iletişim ağı rolünü üstlenmiştir. Sanatın birey ve toplumlar arası iletişim gücüne güç katan dijital/ sanal ağ, yazılı sanat dallarının sanal okuyucuya ulaştığı e-kitap, e-dergi, e-kütüphane gibi sanal mekânların ve e-roman, e-öykü, e-şiir gibi dijital sayfaların oluşmasını sağlamıştır.

$\mathrm{Bu}$ çerçeveden bakıldığında, dijital ortamlarda oluşturulan eserlerin yazılması, sanatsal açıdan değerlendirilmesi ve okuyucu ile iletişim aşamaları vardır. Dijital eserlerin ölçme ve değerlendirilmesi konusunda üç aşamanın önemli olduğu tespit edildi: 1- Eserin özgün olarak bilgisayar ortamında üretilmesi, 2- Önemli edebi özelliklere sahip olması, 3- Sanal ağ üzerinden okunması ve paylaşılması. Eserin özgün olarak ortaya çıkışı ele alındığında, şöyle bir sorun ortaya çıkmaktadır; örneğin bir şiir kâğıt üzerine de yazılsa, bilgisayar klavyesiyle de yazılsa, eski bir daktilo ile de yazılsa yine de bir şiirdir. Ölçme ve değerlendirme aşaması ise, basılı edebiyat dünyasındaki ilkelerle karşılaştırılarak tartışılabilir; basılı edebiyatta, bir eserin belirli edebi özelliklere sahip olup olmadığına, böylece basılmaya değer olup olmadığına alanın hocaları kabul edilen ve aynı alanda belirli bir akademik birikime sahip olan hakem kurulu karar verir. Daha önemlisi, edebi etik açısından düşünüldüğünde, bir şiirin bir şair tarafından yazılmış olma beklentisi vardır; her deneyim şiir, her deneyimin yazarı şair kabul edilmez. Öte yandan, bir eserin birçok okuyucu tarafından beğenilmesi önemli edebi özelliklere sahip olduğunu doğrulamaz veya önemli edebi özelliklere sahip olan eserlerin çok sayıda okuyucu kitlesi olmayabilir. Bu aşamanın elektronik safhasına bakıldığında, her bireyin, edebi özelliklere sahip olsun olmasın, bilgisayar veya farklı ortamlarda yazdığı metni, sanal ağ aracılığıyla, istediği sayfa ya da sitelere gönderme özgürlüğü vardır. Bu, basın dünyasındaki hakem kurulunu devre dışı bırakmak ve metnin kim tarafından yazıldığının hiçbir öneminin olmadığı anlamına gelmektedir. Sanal dünyadaki ölçme ve değerlendirme çoğunlukla beğeni geri dönüşleriyle gerçekleşmektedir. Günümüzde sanatsal yetileri olsun olmasın, teknolojiyle tanışmış ve ondan yararlanmayı bilen hemen her bireyin belirli sayıda takipçisi (izleyici, okuyucu) vardır; bu da paylaşılan görsel, işitsel ya da yazılı metnin, sanatsal veya edebi değerler taşıyıp taşımadığına bakılmaksızın takipçi kitle tarafindan beğenilebileceğini gösterir. Buradan, sayıca çok beğeni alan bir metnin sanatsal ve edebi değerlere haiz bir eser olmayabileceği, böylece sanal dünyadaki ölçme ve değerlendirmenin güvenilir olmadığı sonucuna varılabilir. Son aşama olan, eserlerin sanal ağ üzerinden paylaşımı koşulu, reel basın dünyasıyla karşılaştırıldığında; basın dünyasında, hakem heyetinin değerlendirmesinden geçen basılı eserlerin okuyucu kitle tarafından kabul görmesi satışla ilintili ortaya çıkan envanterle belirlenirken, sanal ağ beğeni sayısının güvenirliği tartışılır. 


\section{Notlar:}

Şiirler, dijital programlamadan elde edilen, anlamlandırılması zor, yapay metinler olduğundan çevirileri yapılmamıştır.

\section{Kaynaklar}

Amerika, M. (2007). Meta a digital poetics. Cambridge: The MIT.

Arnold, D. D. (2007). Poetry and language writing objective and surreal. Liverpool: Liverpool University.

Beach, C. (2003). The Cambridge introduction to twentieth-century American Poetry. New York: Cambridge University.

Bernstein, D. ve Hatch, W. C. (Eds). (2001). Writings through John Cage's music, poetry, and art. Chicago ve London: University of Chicago.

Cage, J. (1961). Silence: Lectures and writings. Hanover: University Press of New England.

Cage, J. (1979). Empty words: writings '73 -'78. Middletown: Wesleyan University.

Ellingham, L. ve Killian, K. (1998). Poet be like god; Jack Spicer and the San Francisco renaissance. Honover ve London: Wesleyan University.

Fredman, S. (Ed). (2005). A concise companion to twentieth-century American poetry. Oxford, UK: Wiley-Blackwell.

Glazier, L. P. (2002). Digital poetics hypertext, visual-kinetic text and writing in programmable media. Tuscaloosa, Alabama: University of Alabama.

Halsey, F. E. (1995). Understanding the black mountain poets. South Carolina: University of South Carolina.

Hayles, N. K. (2008). Electronic literature new horizons for the literary. Notre Dame: University of Notre Dame.

Jeffries, L. (1993). The language of twentieth-century poetry. United Kingdom: Macmillan.

Kimmelman, B. (Ed). (2005). The facts on file companion to 20th century American poetry. New York, NY: Checkmark.

Ledesma, E. (2016). Radical poetry_aesthetics, politics, technology, and the Ibero-American avantgardes, 1900-2015. New York, NY: State University of New York.

Low, J. M. (2008). Thing of beauty: New and selected works. Berkeley, Los Angeles, London: University of California.

Rothenberg, J., Pierre, J. (Ed.). (1998). Poems for the millennium: The University of California book of modern \& postmodern poetry, vol. II: from post war to millennium. Berkeley: University of California.

Richard, R., Bradbury, M. (1991). From puritanism to postmodernism a history of American literature. New York, NY: Penguin.

Silverman, K. (2010). Begin again; a biography of John Cage. New York, NY: Knopf Doubleday.

Simanowski, R. (2011). Digital art and meaning reading kinetic poetry, text machines, mapping art, and interactive installations. Minneapolis \& London: University of Minnesota Press.

Wagner-Martin, L. (2013). A history of American literature: 1950 to the present. West Sussex: Blackwell. 